\title{
Management of iatrogenic urorectal fistulae in men with pelvic
} cancer

\author{
Francisco E. Martins, MDi,2; Natália M. Martins, MD²; Luís Campos Pinheiro, MD; Luís Ferraz, MD"; \\ Luís Xambre, MDi; Tomé M. Lopes, $M D^{1}$
}

'Department of Urology, University of Lisbon, School of Medicine, Hospital Santa Maria (CHLN), Lisbon; ' Unidade Local de Saúde do Norte Alentejano (ULSNA), Portalegre; ${ }^{3}$ Department of Urology, Centro Hospitalar Lisboa Central/Hospital S. José (CHLC), Lisbon; ${ }^{4}$ Department of Urology, Centro Hospitalar Vila Nova de Gaia/Espinho (CHVNG/E), Vila Nova Gaia; Portugal

Cite as: Can Urol Assoc J 2017;11 (9):E372-8. http://dx.doi.org/10.5489/cuaj.4427

Published online September 12, 2017

\section{Abstract}

Introduction: Urorectal fistula (URF) is a devastating complication of pelvic cancer treatments and a surgical challenge for the reconstructive surgeon. We report a series of male patients with URF resulting from pelvic cancer treatments, specifically prostate $(\mathrm{PCa})$, bladder $(\mathrm{BCa})$, and rectal cancer $(\mathrm{RCa})$, and explore the differences and impact on outcomes between purely surgical and non-surgical treatment modalities.

Methods: Between October 2008 and June 2015, 15 male patients, aged 59-78 years (mean 67), with URF induced by pelvic cancer treatments were identified in our institutions. Patients with a history of diverticulitis, inflammatory bowel disease, or other benign conditions were excluded. We reviewed the patients' medical records for symptoms, diagnostic tests performed, type and etiology of the fistula, type of surgical reconstruction, followup, and outcomes.

Results: Fourteen patients underwent surgical reconstruction. One patient developed metastatic disease before URF repair and, therefore, was excluded from this study. Mean followup (FU) was 32.7 months (14-79). All patients received diverting colostomy and temporary urinary diversion. An exclusively transperineal approach was used in nine $(64.3 \%)$ patients and a combined abdominoperineal in five (35.7\%). Overall successful URF closure was achieved in 12 $(85.7 \%)$ patients, nine $(64.3 \%)$ of whom at the first reconstructive attempt, two (14.3\%) after two attempts (in our institution), and one (7.1\%) after three attempts (two of which elsewhere). An interposition flap was used in seven $(50 \%)$ patients. Surgical reconstruction failed ultimately in two (14.3\%) patients who still have a colostomy and do not wish any further reconstruction.

Conclusions: Our study has several limitations, including its retrospective nature and the heterogeneity of our small patient cohort. Nonetheless, although surgical reconstruction of URF may be extremely difficult and complex in the non-surgical/energy ablation patients, its successful reconstruction is possible in most through a transperineal, or a more aggressive abdominoperineal, approach with tissue interposition in selected patients.

\section{Introduction}

Urorectal fistulae (URF) are a devastating complication of modern pelvic cancer treatments and are usually associated with debilitating morbidity and significant impact on quality of life (QoL). Despite its increasing incidence due to the expanding use of new energy ablation technology and new treatment protocols in pelvic cancer, URF remain relatively uncommon, their incidence varying widely from $0.4-3 \%{ }^{-1,2}$ however, due to the adoption of these new therapeutic protocols for the current treatment of pelvic malignancies, the complication paradigm has also changed, leading to a distinction between those resulting from purely surgical treatment and those following non-surgical, energy-ablative treatments, i.e., external beam radiotherapy (EBRT), brachytherapy (BT), high-intensity focused ultrasound (HIFU), cryotherapy, and a combination of these. Therefore, most URF have an iatrogenic etiology, resulting from surgery, radiotherapy, or multimodal protocols, including salvage surgery, for the management of pelvic cancers.

Two distinct scenarios should be observed and discussed separately, as they portend two different outcomes in terms of treatment and prognosis: 1) URF associated with surgery (radical prostatectomy, radical cystectomy, transurethral resection, and rectal resection); and 2) URF secondary to non-surgical, energy-ablation treatments. ${ }^{2}$ The post-surgical URF patients are relatively easy to treat, with rapid recovery and return to daily routine activities. In contrast, URF patients following non-surgical treatments are more problematic and have a much slower return to a more compromised level of daily activities and overall recovery. ${ }^{1}$

Management of URF is challenging and often frustrating for the reconstructive surgeon. Spontaneous closure may rarely occur in very small fistulae not caused by irradiation and after fecal and urinary diversion. ${ }^{3,4}$ Therefore, failure of conservative treatment mandates surgical intervention. Several techniques have been employed for decades to treat URF, including transperineal, abdominoperineal, trans-ano-rectal 
sphincter splitting (York-Mason), perianal rectal advancement flap (Parks), posterior transsacral (Kraske), and variants; ${ }^{1,5-8}$ however, despite all these reported surgical possibilities, the single "best" procedure is still a topic of intense debate.

We report a series of male patients with URF resulting from pelvic cancer treatments and explore the differences and impact on outcomes between purely surgical and nonsurgical treatment modalities, as well as drawing attention to the challenging nature of repair.

\section{Methods}

\section{Patients}

Between October 2008 and February 2015, we treated 14 male patients with urorectal fistulae in our institutions. One patient following anterior rectal resection developed liver and lymph node metastases four months after URF diagnosis, while on antibiotic and conservative treatment of a pelvic infection/sepsis and, therefore, was excluded from this study. The patients' medical records were retrospectively reviewed for demographic data, symptoms, fistula characteristics, type of fistula repair, followup, and outcomes. All patients underwent digital rectal examination and flexible cystourethroscopy (Fig. 1). Retrograde urethrogram, pelvic computed tomography $(\mathrm{CT})$ with $3 \mathrm{D}$ reconstruction, and magnetic resonance imaging (MRI) were also included in the routine preoperative assessment (Figs 2, 3). Two patients following anterior rectal resection received barium enema with fistulogram and rectosigmoidoscopy requested by their referring general/colorectal surgeons. Patients with fistulae due to benign causes were excluded.

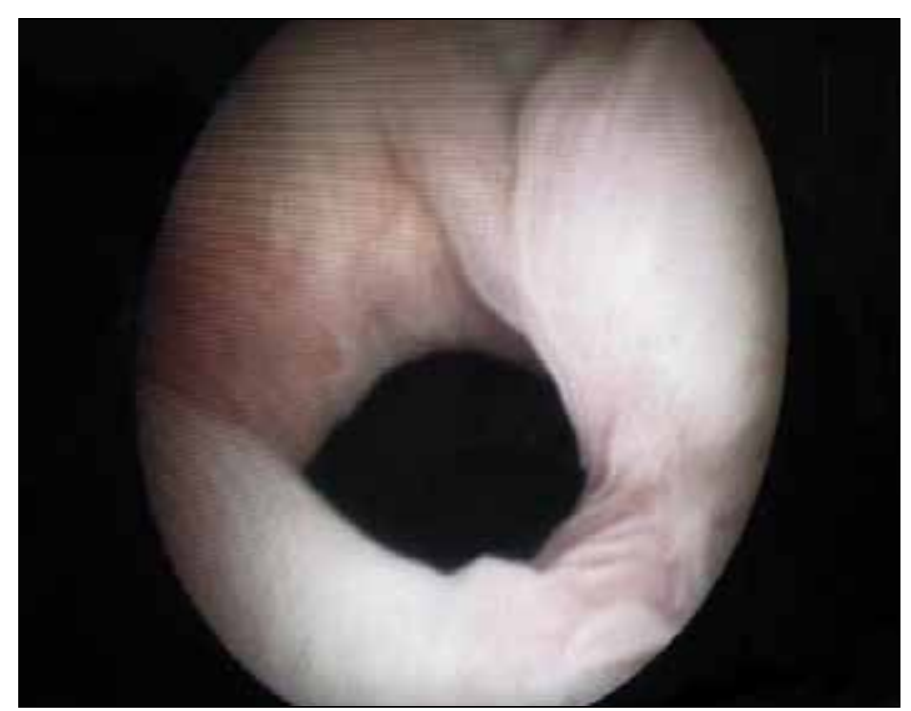

Fig. 1. Cystourethroscopy of giant urorectal fistula located at the prostatic urethra and bladder neck.
All 14 patients presented urine leakage through the rectum; however, fecaluria was noted by only four (28.5\%) patients. In three patients treated with combined radiotherapy and surgery, an infected pelvic cavity mandating surgical drainage and in-hospital parenteral antibiotic treatment was required. Three patients who received radiotherapy and HIFU presented with rectal, pelvic/perineal pain of varying degree and rectal bleeding.

Eight $(57.1 \%)$ patients received some form of radiotherapy, either EBRT or BT, or both, and in combination with surgery (anterior rectal resection, radical prostatectomy, transurethral resection of prostate [TURP] or of bladder tumor) or HIFU, and therefore were included in the group of URF induced by energy ablation (Group 1) (Table 1). In six $(42.9 \%)$ patients, the etiology was purely surgical, i.e., open radical prostatectomy in two patients, laparoscopic radical prostatectomy in two, radical cystectomy and orthotopic urinary reconstruction in one, and anterior rectal resection in one (Group 2). The time interval between the development of the fistula and our urological observation varied between one and 15 months. Out of 12 patients whose fistula was successfully repaired, one had already had two previous failed surgical attempts (York-Mason followed by transabadominal) and two patients had already been submitted to one failed attempt (York-Mason in both). In two (14.3\%) patients, closure of the fistula tract was not possible and, therefore, these were considered surgical failures. One of these patients had received BT followed by EBRT and one had received HIFU and EBRT (Group 1). One of the URF patients after anterior rectal resection developed an associated urethroperineal fistula and underwent resection of his residual rectum because of local tumour recurrence.

\section{Surgical repair}

An exclusively transperineal approach was used in nine $(64.3 \%)$ patients and a combined abdominoperineal approach in the remaining five $(35.7 \%)$. The decision to opt for a combined abdominoperineal approach was based primarily on local tissue integrity/health, fistula characteristics, and mainly, on radiation/energy ablation exposure. Interposition of vascularized flaps was used in seven (50.0\%) patients, gracilis muscle (Fig. 4) in four patients, and omentum in three. All patients had a diverting colostomy and urinary diversion (suprapubic cystostotomy or indwelling urethral catheterization) at the time of urological referral. Patients were placed in a slightly exagerated lithotomy position and an inverted $U$ incision was made with both ischial tuberosities as lateral limits and $2 \mathrm{~cm}$ below the scrotum as the upper limit. A $7 \mathrm{~F}$ ureteric guidewire was placed transurethrally under endoscopic guidance whenever necessary or possible to facilitate fistula identification. Dissection commenced bilaterally through both ischiorectal fossa, develop- 


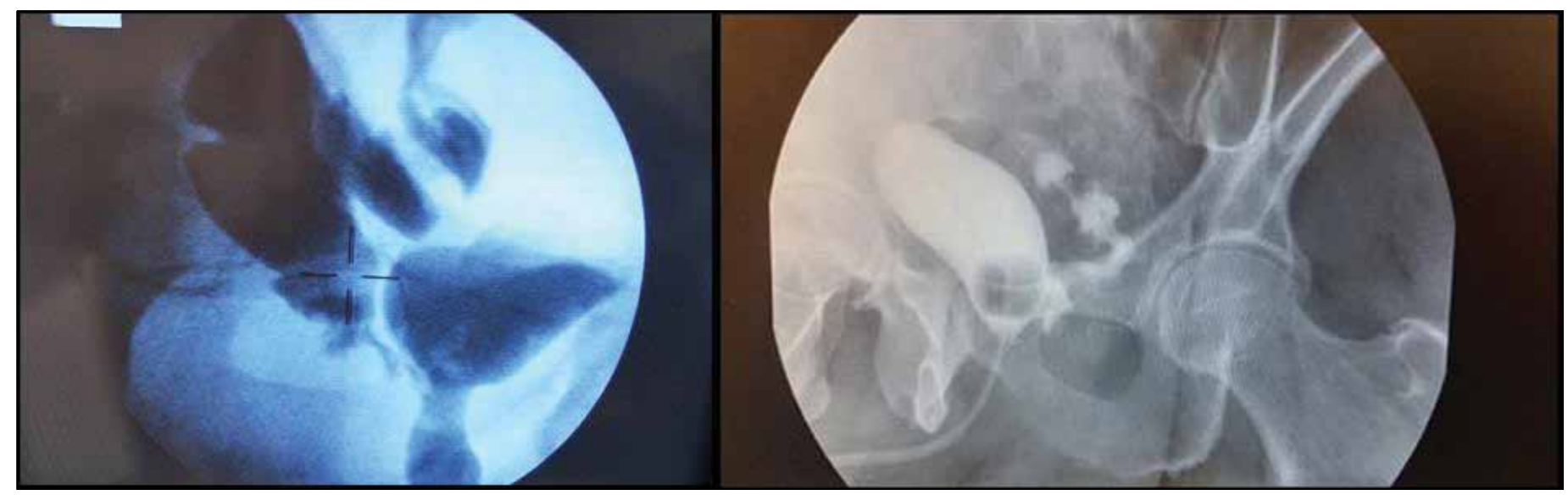

Fig. 2. Retrograde and voding cystourethrogram of a patient with urorectal fistula showing (A) the fistulous tract between bladder neck and rectum; and (B) the opening of the vesico-sigmoid fistulous tract above the bladder neck during bladder filling in a different patient.

ing a plane to separate the anterior rectal wall from the ventral aspect of the posterior urethra. In patients with prostate in place, the urinary side of the fistula was closed primarily at its urethral end followed, in some, by interposition of a vascularized flap. A simultaneous anastomotic posterior urethroplasty was needed in two patients. Two patients following RP (open and laparoscopic) required vesicourethral re-anastomosis, although this was also deemed necessary in a third patient, i.e., in one of the two patients who refused further reconstruction. The urinary side of the fistula was closed longitudinally in one plane and the rectal side was closed horizontally to maximize lumen circumference, in two planes whenever possible.

Both urinary and fecal diversions were always kept temporarily after URF closure. A retrograde and voiding cystourethrogram was performed 6-8 weeks after reconstruction. Both indwelling urethral catheter and suprapubic cystostomy were removed if there was no radiographic leak and the urethral healing appeared satisfactory endoscopically. Colostomy closure was recommended 4-6 months after successful URF closure.

The success of this reconstruction was defined as spontaneous urethral voiding without leakage from the rectum.

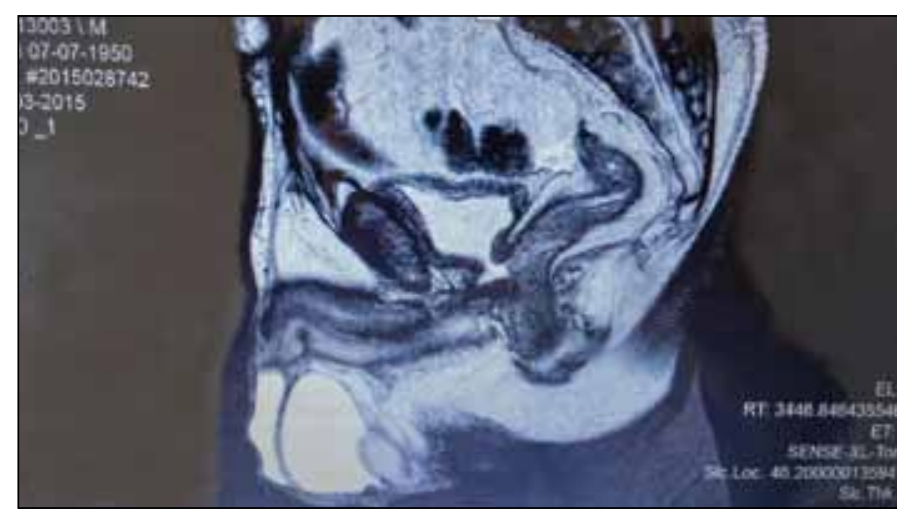

Fig. 3. Magnetic resonance imaging of urorectal fistula between the prostatic urethra and rectum.
Urinary incontinence after URF closure was not considered fistula reconstructive failure. All patients were previously informed about the possibility of further treatment for urinary incontinence.

\section{Results}

Patient age ranged from 59-78 years (mean 67). Patients were divided into two groups: Group 1 included eight (57.1\%) patients who received energy-ablation treatments (EBRT, BT, or HIFU) as monotherapy or in combination with surgery, and Group 2 included six (42.9\%) patients who had only surgery. Ten patients developed URF following treatment for prostate cancer (PCa): three patients after low-dose brachytherapy (LDB) combined with EBRT; five after radical prostatectomy (open in three patients and laparoscopic in two) with adjuvant EBRT in one of them; one patient after LDB followed by TURP due to prostatic obstruction; and one after combined HIFU and EBRT. Two patients developed URF after bladder cancer treatment (one after neoadjuvant chemotherapy plus radiotherapy followed by TURBT and one after radical cystectomy and ileal neobladder), and two after anterior rectal resection (ARR), with adjuvant EBRT in one (Table 2). No spontaneous fistula closure was observed in any patient.

Fourteen patients underwent URF surgical repair through a transperineal approach in nine and an abdominoperineal in five. Clinical characteristics of patients and surgical outcomes of URF repair are summarized in Tables 2 and 3. Overall successful closure of the fistula was achieved in a total of $12(85.7 \%)$ patients. Surgical reconstruction failed in two patients, who declined further surgery. Followup was available for all 14 patients and ranged from 14-79 months (mean 32.7).

All patients developed some degree of urinary incontinence (stress and mixed), probably multifactorial in origin, due to iatrogenic injury of the rabdosphincter and/or detrusor dysfunction, either because of direct surgical injury, or 


\begin{tabular}{|c|c|}
\hline $\begin{array}{l}\text { Group 1: Non- } \\
\text { surgical/energy } \\
\text { ablation) }\end{array}$ & $\begin{array}{l}\text { External beam radiotherapy } \\
\text { Brachytherapy } \pm \text { TURP } \\
\text { High-intensity focal ultrasound }\end{array}$ \\
\hline Group 2 (Surgical) & $\begin{array}{c}\text { Radical prostatectomy (open, laparoscopic) } \\
\text { Radical cystectomy (open) } \\
\text { Anterior rectal resection (open) }\end{array}$ \\
\hline
\end{tabular}

because of irradiation/HIFU, or both. Of the six patients in Group 1 who underwent successful URF closure, an AMS800 ${ }^{\circledR}$ artificial urinary sphincter was placed in three (one after RP + EBRT, one after BT + TURP, and one after $A R R+E B R T)$. In Group 2, only one patient received an artificial urinary sphincter. The remainder tolerated their mild incontinence well under oral antimuscarinic treatment and with use of pads and, therefore, do not wish further surgery. All patients, including those who have an artificial urinary sphincter, wear 1-2 pads daily for protection or hygiene reasons. All but two patients had their colostomy closed between four and six months after URF successful repair.

Erectile dysfunction, varying from moderate to severe, was reported by all patients.

\section{Discussion}

URF following genitourinary and colorectal cancer treatments are relatively uncommon, but a difficult reconstructive challenge for the surgeon. Furthermore, it carries a devastating physical and psychological impact for the patient. Most URF have an iatrogenic origin, due to surgery, mostly associated with treatment of prostate cancer and, less com-

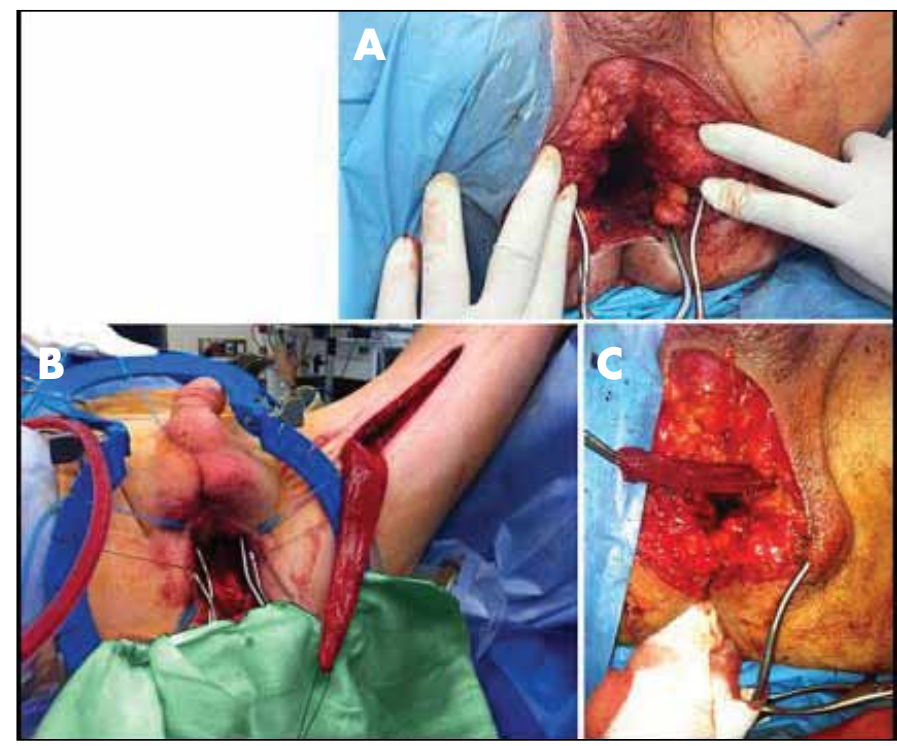

Fig. 4. Interposition of gracilis muscle flap in urorectal fistula repair: (A) surgical exposure of the perineal area; $(\boldsymbol{B})$ harvesting of gracilis muscle; and (C) transposition of gracilis muscle into the perineum. monly rectal and bladder cancers. With the exponential and widespread use of "minimally invasive" energy-ablation treatments - supposedly less aggressive for the patient (especially to treat prostate cancer) - we have witnessed a significant increase in three types of vesicourethral complications in the last decades, which should be discussed in the same context. It is ironic that many of these patients are strongly advised to opt for less invasive and less aggressive treatment modalities to avoid surgery-related morbidity, and that some of them end up with much more devastating, catastrophic, incapacitating, and more-difficult-to-treat complications associated with these "minimally invasive" options.

Diagnosis of URF is relatively easy and obvious: urine loss through the rectum, which happened in all our patients. Although less commonly, some of our patients also complained of pneumaturia and fecaluria. These symptoms denote a higher location of the fistula, usually vesico-rectal or vesico-sigmoid. Preoperative evaluation included cystourethroscopy and retrograde/voiding cystourethrogram in all patients, and in two of them rectosigmoidoscopy and barium enema with fistulography. Although the two latter have diagnostic merits and, therefore, are requested preferentially by colorectal surgeons, urologists favour URF diagnosis on tests performed through the urinary tract due to higher familiarity and, more importantly, because the pressure gradient in these fistulae is usually from the urinary to the intestinal side, except for fistulae of higher location. We think it is essential that these patients are assessed by pelvic MRI to better characterize the anatomy, location, and involvement of neighbouring structures.

Although some authors do not think colostomy before surgery to be critical, especially in URF of a purely surgical origin, we find it safe and prudent, particularly in lowvolume centres or for surgeons with limited experience and, therefore, we recommend it always. ${ }^{1,9-11}$ Others recommend a colostomy mainly in the radiation/energy-ablation setting due to more significantly impaired tissue conditions and to reduce inflammation. ${ }^{12}$ We could not avoid permanent fecal and urinary diversion in two patients after previously failed repairs due to the severely fibrotic local tissues and, consequently, extremely difficult reconstruction.

Spontaneous URF closure has been reported in the literature; ${ }^{3-5}$ however, no URF closed spontaneously in our series, although we admit that possibility in small, uncomplicated URF resulting from surgery.

In our series, to consent to surgery patients were informed that this type of reconstruction might eventually be a fourstage procedure: creation of diverting colostomy (and simultaneous urinary diversion), URF closure, colostomy closure, and implantation of an artificial urinary sphincter.

We used a transperineal approach in most patients and an abdominoperineal approach in some. In nine (64.3\%) patients, one single surgical repair was sufficient to close the 


\begin{tabular}{|c|c|c|c|c|c|c|c|c|c|c|}
\hline Patient & $\begin{array}{l}\text { Age } \\
\text { (yrs) }\end{array}$ & Etiology & $\begin{array}{c}\text { Location/fistula } \\
\text { type }\end{array}$ & $\begin{array}{l}\text { Previous } \\
\text { attempts }\end{array}$ & Surgical approach & $\begin{array}{l}\text { Ureteric } \\
\text { stent }\end{array}$ & $\begin{array}{l}\text { Temporary } \\
\text { colostomy }\end{array}$ & $\begin{array}{c}\text { Flap } \\
\text { interposition }\end{array}$ & Outcomes & $\begin{array}{l}\text { FU } \\
\text { (M) }\end{array}$ \\
\hline 1 & 62 & $\begin{array}{c}\text { Brachy + } \\
\text { EBRT }\end{array}$ & Prostatic urethra & 0 & Perineal & Yes & Yes & $\begin{array}{l}\text { Gracilis } \\
\text { muscle }\end{array}$ & Failure & 46 \\
\hline 2 & 68 & $\begin{array}{c}\text { Brachy + } \\
\text { TURP }\end{array}$ & $\begin{array}{l}\text { Membran-ous and } \\
\text { prostatic urethra }\end{array}$ & 0 & Abdominoperineal & No & Yes & Omentum & $\begin{array}{l}\text { Success after } \\
1 \text { attempt }\end{array}$ & 40 \\
\hline 3 & 59 & $\begin{array}{c}\text { Brachy + } \\
\text { EBRT }\end{array}$ & BN/LT & 1 & Perineal & No & Yes & $\begin{array}{l}\text { Gracilis } \\
\text { muscle }\end{array}$ & $\begin{array}{l}\text { Success after } \\
2 \text { attempts }\end{array}$ & 30 \\
\hline 4 & 73 & ARR & $\mathrm{BN} / \mathrm{LT}$ & 0 & Perineal & No & Yes & None & $\begin{array}{l}\text { Success after } \\
1 \text { attempt }\end{array}$ & 44 \\
\hline 5 & 75 & Lap RP & $\begin{array}{c}\text { Giant fistula } \\
\text { involving prostatic } \\
\text { urethra and } B N / L T\end{array}$ & 2 & Abdominoperineal & No & Yes & $\begin{array}{l}\text { Gracilis } \\
\text { muscle }\end{array}$ & $\begin{array}{l}\text { Success after } \\
3 \text { attempts }\end{array}$ & 56 \\
\hline 6 & 78 & $\begin{array}{l}\mathrm{ARR}+ \\
\mathrm{EBRT}\end{array}$ & BN/LT & 0 & Abdominoperineal & Yes & Yes & $\begin{array}{c}\text { Gracilis + } \\
\text { proctectomy }\end{array}$ & $\begin{array}{l}\text { Successful } \\
\text { after } 1 \\
\text { attempt }\end{array}$ & 79 \\
\hline 7 & 66 & $\begin{array}{l}\mathrm{RRP}+ \\
\mathrm{EBRT}\end{array}$ & BN/LT & 1 & Abdominoperineal & Yes & Yes & Omentum & $\begin{array}{l}\text { Successful } \\
\text { after } 2 \\
\text { attempts }\end{array}$ & 32 \\
\hline 8 & 64 & RRP & Prostatic urethra & 0 & Perineal & No & Yes & None & $\begin{array}{l}\text { Success after } \\
1 \text { attempt }\end{array}$ & 26 \\
\hline 9 & 61 & $\begin{array}{l}\text { HIFU + } \\
\text { EBRT }\end{array}$ & Prostatic urethra & 0 & Perineal & No & Yes & None & Failure & 16 \\
\hline 10 & 63 & Lap RP & Prostatic urethra & 0 & Perineal & No & Yes & None & $\begin{array}{l}\text { Success after } \\
1 \text { attempt }\end{array}$ & 18 \\
\hline 11 & 59 & RRP & BN/LT & 0 & Perineal & No & Yes & None & $\begin{array}{l}\text { Success after } \\
1 \text { attempt }\end{array}$ & 17 \\
\hline 12 & 71 & $\begin{array}{c}\text { Chemo + } \\
\text { EBRT + } \\
\text { TURBT }\end{array}$ & Trigone/BN & 0 & Perineal & Yes & Yes & None & $\begin{array}{l}\text { Success after } \\
1 \text { attempt }\end{array}$ & 24 \\
\hline 13 & 67 & $\begin{array}{c}\text { Brachy + } \\
\text { EBRT }\end{array}$ & Prostatic urethra & 0 & Abdominoperineal & No & Yes & Omentum & $\begin{array}{l}\text { Success after } \\
1 \text { attempt }\end{array}$ & 14 \\
\hline 14 & 75 & $\begin{array}{c}\mathrm{RC}+\text { ileal } \\
\text { beobladder }\end{array}$ & $\begin{array}{l}\text { Neovesico- } \\
\text { urethral anasto- } \\
\text { mosis }\end{array}$ & 0 & Perineal & No & Yes & None & $\begin{array}{l}\text { Success after } \\
1 \text { attempt }\end{array}$ & 18 \\
\hline
\end{tabular}

ARR: anterior resection of rectum; BN/LT: bladder neck/ low trigonal; EBRT: external beam radiotherapy; FU: followup; HIFU: high-intensity focused ultrasound; Lap RP: laparoscopic radical prostatectomy; M: months; RC: radical cystectomy; RRP: radical retropubic prostatectomy; TURP: transurethral resection of prostate.

URF successfully. An abdominoperineal approach was used in the five more difficult URF patients with dense pelvic tissue fibrosis, i.e., in four patients with history of previous energy ablation and in one patient following three reconstructive attempts, two of them elsewhere, to repair a URF caused by laparoscopic radical prostatectomy. Although we recognize merits and efficacy in other techniques described in the literature, we believe that the advantages of the transperineal approach are the following: effective separation between urinary tract and rectum, separate closure of both ends of fistula, possibility of vascularized flap interposition without the need of a second separate incision, possibility of a twoplane, easier closure of the rectal side of the fistula, its feasibility even after previously failed repair attempts and, finally, the possibility of performing this procedure in one stage only with no need for colostomy. The transperineal approach is usually favoured by urologists, who perform these operations themselves, as they feel more familiar with the perineal anat- omy and with this "classical" urological approach to treat urological and other pelvic cancer complications involving the urinary tract. ${ }^{1}$ We think the transperineal approach is currently the most commonly used method for URF repair. On the other hand, in our opinion, access to the urinary tract is more difficult in the York-Mason procedure: 1 ) it cannot be used in large and complex fistulae; 2 ) it should be avoided in patients with severe radiation proctitis; 3 ) the operation is generally performed by general/colorectal surgeons; 4) the interposition of a vascularized flap requires a second incision; 5) the incidence of recto-cutaneous fistulation is higher; and 6) we do not see a reason for a risky and unnecessary division of the anal sphincter complex (both internal and external anal sphincters) with subsequent flatus incontinence and fecal soiling, although not true fecal incontinence.,13-16 This issue has been described superficially, insufficiently, or even ignored, in most York-Mason literature. ${ }^{6,11,17,18}$ Although popular between the 1960s and 1980s for the surgical treat- 


\begin{tabular}{|c|c|c|c|c|c|c|c|c|c|c|}
\hline \multirow{2}{*}{ Patient groups } & \multirow{2}{*}{ Failures } & \multicolumn{3}{|c|}{ Surgical success after $X$ attempts } & \multirow[t]{2}{*}{ Total } & \multicolumn{2}{|c|}{ Surgical approach } & \multirow[t]{2}{*}{ Total } & \multicolumn{2}{|c|}{ Interposition flap } \\
\hline & & 1 & 2 & 3 & & Perineal & Abd-perineal & & Gracilis muscle & Omentum \\
\hline $\begin{array}{l}\text { G1 (Non- } \\
\text { surgical) }\end{array}$ & 2 & 4 & 2 & 0 & 8 & 4 & 4 & 8 & 3 & 3 \\
\hline G2 (Surgical) & 0 & 5 & 0 & 1 & 6 & 5 & 1 & 6 & 1 & 0 \\
\hline Total & $2(14.3 \%)$ & $9(64.3 \%)$ & $2(14.3 \%)$ & $1(7.1 \%)$ & $14(100 \%)$ & $9(64.3 \%)$ & $5(35.7 \%)$ & $14(100 \%)$ & $4 / 14(28.5 \%)$ & $3 / 14(21.5 \%)$ \\
\hline
\end{tabular}

ment of small rectal cancers and adenomas, especially in an era where endoscopic excision of these lesions was nonexistent, ${ }^{6,18-20}$ its popularity has recently been replaced by the transperineal approach by reconstructive surgeons, especially in high-volume centres. ${ }^{9,12,21}$

In our series, an abdominoperineal approach was reserved for patients that were complicated by the development of a cavity in association with energy ablation, such as EBRT, BT, and HIFU. Good surgical access via the perineum is, in most instances, hampered by unhealthy tissues, which are generally more difficult to mobilize and reach in depth. Moreover, in most of these patients, salvage procedures (e.g., salvage radical prostatectomy) and omental wrap are required to achieve satisfactory results. The two failures in our study were in the energy-ablation cohort and, although they underwent abdominoperineal approach, the fistula could not be closed successfully and thus, it was decided not to attempt any further.

Because the use of radiation or any other form of energy ablation adds complexity to URF repair and increases local morbidity, such as dense tissue fibrosis and associated urethral and rectal strictures, pelvic cavitation and abscess, and pelvic/perineal and rectal pain, we think it is relevant to discuss iatrogenic URF in two distinct scenarios due to the therapeutic implications, success, and prognosis: 1) URF caused by surgery; and 2) URF resulting from non-surgical, energy-ablation-related iatrogeny, such as primary or adjuvant EBRT, BT, cryotherapy, HIFU alone or in combination protocols. Globally, our surgical group patients were easier to treat, had less complications, and were associated with a shorter recovery and quicker return to their daily routine activities and bodily functions compared to the non-surgical group. All our surgical group patients were cured at the first surgical attempt. One such patient, however, needed three repair attempts, two of them elsewhere. Overall postoperative success rate was $85.7 \%$ (12/14 patients); however, $100 \%$ success was achieved in Group 2 (6/6 patients) compared to $75 \%$ in Group 1 (6/8 patients) (Table 3). The two failures occurred in the Group 1 patients who had received heavy irradiation, combined with HIFU in one. These patients developed significant tissue fibrosis and devascularization, which prevent normal tissue healing, occasionally even with interposition of a vascularized flap, as shown by some authors. ${ }^{1,12,22}$ In our study, all patients in the non-surgical group received more than one therapeutic modality (Table
2 ), stressing the concept of potentiation of deleterious and cumulative effects following irradiation.

In our series, mean followup of 32.7 months (14-79) revealed no evidence of fistula recurrence in any of the successfully treated patients. Some degree of stress or mixed urinary incontinence was reported by all our patients; however, only four $(28.5 \%)$ patients considered their incontinence to be severe enough to necessitate insertion of an artificial urinary sphincter, with the remainder tolerating their incontinence well with help of antimuscarinic drugs and use of pads. Some patients admitted that, after such challenging repair, the wish to avoid further surgery coupled with burdensome convalescence was a reason for resignation.

Erectile dysfunction was similarly reported by all patients in our study. Interestingly, no patient has required surgical treatment, including placement of a penile prosthesis. Four patients in Group 2 and none in Group 1 have responded to oral PDE-5 inhibitors. Some authors have reported that preservation of potency, urinary incontinence, and rectal innervation is possible after the York-Mason operation because it avoids dissection in the lateral pelvic and pararectal space. ${ }^{11}$ We believe that in most URF patients, these complications result primarily from the oncological treatments that cause the fistula rather than the surgical repair.

Some authors have questioned the need for interposing vascularized flaps in URF repair. ${ }^{11}$ Although we have used tissue interposition in a total of seven (50\%) patients, six of them after some form of energy ablation (Group 1), we, like others, do not think it is crucial to use it in URF caused exclusively by surgery, where tissue injury is less significant and extensive (except for a previously failed URF repair). ${ }^{12}$ Therefore, we do not recommend the routine and indiscriminate use of this adjuvant procedure, particularly in URF caused exclusively by surgical trauma; it should be used judiciously and with caution to avoid additional morbidity associated with these procedures.

We recognize the limitations in our study, especially the retrospective nature of the analysis, the limited number of a heterogeneous cohort of patients rendering statistical analysis impossible, a complex learning curve, and the fact that all patients were operated on by the same surgeon, which may not necessarily be an advantage. We also are aware that the success rates tend to be naturally lower in less experienced hands and lower-volume centres; ${ }^{21}$ however, these limitations do not decrease the clinical importance 
of our data. In our study, mean followup is 32.7 months and only patients with followup $\geq 12$ months were included, as some patients had their urinary diversion reversed and colostomy closed after 4-6 months, which attests to the apparently definitive outcomes in our series. Moreover, we should stress the importance of the learning curve of this repair and, lastly, that the choice of the surgical approach should rely primarily on surgeon's experience, preference and familiarity with a specific technique, as well as fistula and patient characteristics.

\section{Conclusion}

Although increasing in incidence, iatrogenic URF remain an uncommon complication of pelvic cancer treatments with a devastating physical and psychological impact usually associated with incapacitating morbidity and deterioration of QoL. Its successful resolution is possible in most patients through a transperineal or an abdominoperineal approach with interposition of healthy, vascularized flaps, in select settings. When counselling patients about surgical vs. nonsurgical options as primary treatment for their pelvic cancer, the magnitude and complexity of complications, the ease of treatment of these complications, and the degree of return to normality are in favour of surgery.

Competing interests: The authors report no competing personal or financial interests.

This paper has been peer-reviewed.

\section{References}

1. Mundy AR, Andrich DE. Posterior urethral complications of the treatment of prostate cancer. BJU Int 2012;110:304-25. https://doi.org/10.1111/i.1464-410X.2011.10864.x

2. Choi JH, Jeon BG, Choi SG, et al. Rectourethral fistula: Systematic review of and experiences with various surgical treatment methods. Ann Coloproctol 2014;30:35-41. https://doi.org/10.3393/ ac.2014.30.1.35
3. Venkatesan K, Zacharakis E, Andrich DE, et al. Conservative management of urorectal fistulae. Urology 2013:81:1352-6. https://doi.org/10.1016/j.urology.2012.10.040

4. Nfonsam VN, Mateka JJ, Prather AD, et al. Short-term outcomes of the surgical management of acquired rectourethral fistulas: Does technique matter? Res Rep Urol 2013;5:47-51.

5. Goodwin WE, Turner RD, Winter CC. Rectourinary fistula: Principles of management and a technique of surgical closure. J Urol 1958;80:246-54. https://doi.org/10.1016/S0022-5347(17)66172-X

6. Vidal Sans J, Palou Redorta J, Pradell Tiegell J, et al. Management and treatment of eighteen rectourethral fistulas. Eur Urol 1985;11:300-5.

7. Ryan JA Jr, Beebe HG, Gibbon RP. Gracilis muscle flap for closure of rectourethral fistula. J Urol 1979;122:124-5. https://doi.org/10.1016/S0022-5347(17)56282-5

8. Parks AG, Moston RW. Peranal repair of rectoprostatic fistula. Br I Surg 1983;70:725-6. https://doi. org/10.1002/bis. 1800701210

9. Mundy AR, Andrich DE. Urorectal fistulae following the treatment of prostate cancer. BJU Int 2011;175:1298-303. https://doi.org/10.1111/j.1464-410X.2010.09686.x

10. Nyam DC, Pemberton JH. Management of iatrogenic rectourethral fistula. Dis Colon Rectum 1999;42:9949. https://doi.org/10.1007/BF02236689

11. Renschler TD, Middleton RG. 30 years' experience with York-Mason repair of recto-urinary fistulas. J Urol 2003;170:1222-5. https://doi.org/10.1097/01.ju.0000082013.58783.17

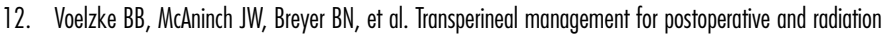
rectourethral fistulas. J Urol 2013;189:966-71. https://doi.org/10.1016/i.juro.2012.08.238

13. Saund MS, Bleday R. Management of rectourethral fistula. In: Andrew P. Zbar, Robert D. Madoff, Steven D. Wexner (Editors). Reconstructive Surgery of the Rectum, Anus and Perineum. 1st Edition. London: Springer-Verlag; 2013, 405-417. https://doi.org/10.1007/978-1-84882-413-3_39

14. Noldus J, Fernandez S, Huland H. Rectourinary fistula repair using the Latzko technique. J Urol 1999;161:1518-20. https://doi.org/10.1016/S0022-5347(05)68942-2

15. Thomas $C$, Jones J, Jäger $W$, et al. Incidence, clinical symptoms, and management of rectourethral fistulas after radical prostatectomy. J Urol 2010;183:608-12. https://doi.org/10.1016/i.juro.2009.10.020

16. Hechenbleikner EM, Buckley IC, Wick EC. Acquired rectourethral fistulas in adults: A systematic review of surgical repair techniques and outcomes. Dis Colon Rectum 2013;56:374-83. https://doi.org/10.1097/ DCR.0b013e318274dc87

17. Kasraeian A, Rozet $F$, Cathelineau $X$, et al. Modified York Mason technique for repair of iatrogenig rectourinary fistula: The Monsouris experience. J Urol 2009;181:1178-83. https://doi.org/10.1016/i. juro.2008.10.160

18. Fengler SA, Abacariab H. The York Mason approach to repair of iatrogenic rectourinary fistulae. Am I Surg 1997;173:213-7. htrps://doi.org/10.1016/S0002-9610(96)00015-3

19. Corman ML. Colon and Rectum Surgery, 1st edition. Philadelphia: Lippincott, 1984

20. Keighley MRB, Williams NS. Surgery of the Anus, Rectum and Colon, 1st edition. Philadelphia: Saunders, 1991

21. Harris CR, McAninch JW, Mundy AR, et al. Rectourethral fistulas secondary to prostate cancer treatment: Management outcomes from a multi-institutional combined experience. J Urol 2017;197:191-4. https://doi.org/10.1016/i.juro.2016.08.080

22. Gotto GT, Yunis $L H$, Vora $K$, et al. Impact of prior prostate radiation on complications after radical prostatectomy. J Urol 2010;184:136-42. https://doi.org/10.1016/i.juro.2010.03.031

Correspondence: Dr. Francisco E. Martins, Department of Urology, University of Lisbon, School of Medicine, Hospital Santa Maria (CHLN), Lisbon, Portugal; faemartins@gmail.com 